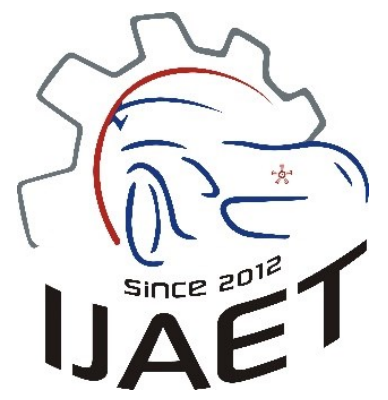

e-ISSN: 2146 - 9067

International Journal of Automotive

Engineering and Technologies

journal homepage:

https://dergipark.org.tr/en/pub/ijaet

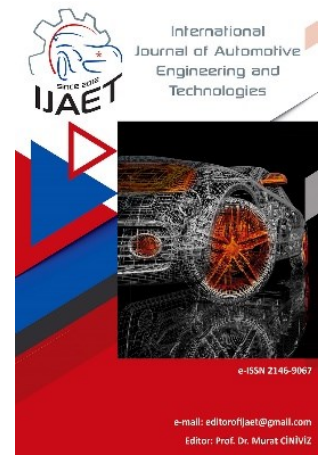

Original Research Article

\title{
Prediction of automotive HVAC duct acoustic properties via innovative simulation techniques
}

\author{
Chandra Shekhar Vishwanadha ${ }^{1}$, Abdullah Emre Özdemir ${ }^{2, ~ *}$, Baha Zafer ${ }^{3}$ \\ ${ }^{1,2}$ Inspirisiontech Engineering, Neue Mainzer Strasse 6-10, WINX Tower, 21. Floor, 60311 Frankfurt am Main, Germany. \\ ${ }^{3}$ Faculty of Aeronautics and Astronautics, Aeronautical Engineering, Istanbul Technical University 34469 Maslak, İstanbul.
}

\begin{abstract}
ARTICLE INFO
1. 0000-0003-0843-2898

2. 0000-0001-9423-6353

3. 0000-0003-0763-9766

Doi: $10.18245 /$ ijaet. 758142

* Corresponding author

emre.oezdemir@inspirisiontech.de

Received: Jun 28, 2020

Accepted: Dec 31, 2020

Published: Mar 31, 2021

\section{Published by Editorial Board Members of IJAET \\ (C) This article is distributed by Turk Journal Park System under the CC 4.0 terms and conditions.}

\begin{abstract}
For the automotive industry, acoustic comfort is of increasing importance. Customer expectations and strong competition in the market play an important role to accelerate vehicle development activities. Although the primary function of HVAC (Heating ventilation and Air-conditioning) is thermal comfort of the occupant during ride; acoustic comfort is also important when it comes to customer satisfaction resulting in overall experience of the vehicle. Hence, prediction of cabin interior noise in the early design stage plays an important role in designing a superior quality product.

In this paper, cabin interior noise levels generated by HVAC systems are predicted by using computational 1-D (one dimensional) analysis. 3-D (three dimensional) CAD geometry is designed using SOLIDWORKS and 1-D analysis is done on GT-Suite. Main purpose of this paper is to demonstrate how 1-D simulation can be an aid for a duct designer by predicting the NVH characteristic of HVAC Ducts and continuing the research to shorten the product development timelines.
\end{abstract}

Keywords: HVAC, Numerical Simulation, Acoustics, 1D Analysis, NVH

\section{Introduction}

Introduction of stringent exhaust emission standards, lightweight materials in design, use of high performance and quieter automotive components has made it challenging for the $\mathrm{NVH}$ (noise, vibration and harshness) engineers, as the target to deliver a quiet and smooth vehicle is becoming difficult with every product life cycle. The market and customer expectation makes the HVAC system noise quality a question to be addressed as early as possible in the vehicle development process [1].
Another tradeoff engineer has to make is between the superior NVH targets and extensive testing required to achieve those targets which can drive up the cost and extend development timelines. Any compromise in either, can lead to an inferior product which can degrade the experience of the end customer or environment if an OEM (Original Equipment Manufacturer) chooses to over design and pursue in over testing the product. The aim of any OEM is to strike a balance between testing and virtual validation to achieve a design which exceeds customer expectations and also doesn't hurt the 
environment during its evolution.

OEM's and their suppliers have been performing many engineering activities to optimize cabin interior noise and vehicle noise. The most common noise sources in a vehicle are generated from the powertrain, tire/road, wind, exhaust and HVAC system. HVAC is an important functional system of the vehicle which along with the thermal comfort for passengers but also owing to condition safety legislations [2]. Although $\mathrm{HVAC}$ is required for thermal comfort of the passenger, the $\mathrm{NVH}$ characteristic of the system has been a key area for the customers [3].

As we are moving towards e-mobility and Battery Electric Vehicles (BEV), the conventional NVH engineering is facing some challenges as the main sources of noise have changed in the newer vehicles. Electrified vehicles are extremely silent compared to combustion engine vehicles due to the absence of combustion engines and other heavy moving parts. In contrast, the electric motor makes very less noise which makes wind and HVAC noise dominant; hence easily susceptible to human ears. The combination of Wind and HVAC Noise along with the EV components has a strong influence on aeroacoustics that makes it a challenging task for the NVH Engineers [4]. Therefore, many companies try to find new ways to analyze the acoustic characteristics of HVAC systems. Figure 1 shows the generic cabin model of airflows that cause noise in the cabin interior.

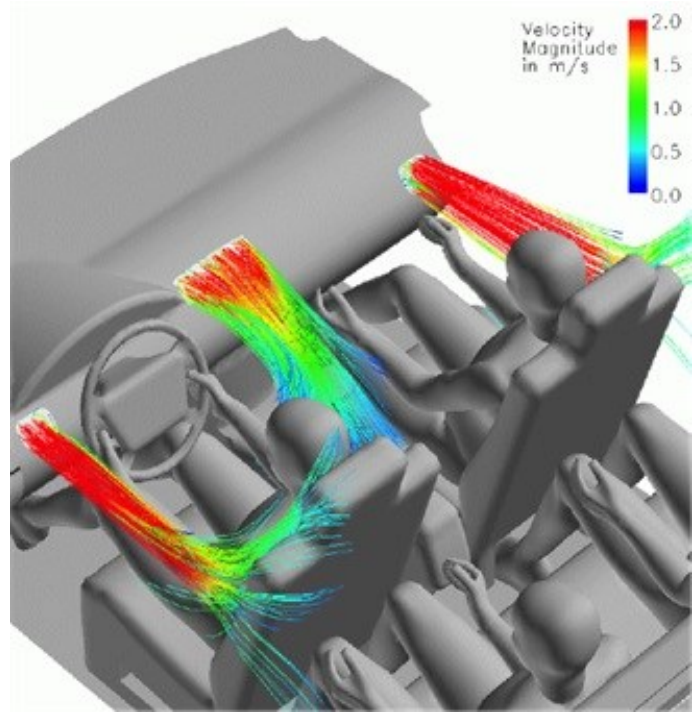

Figure 1. Cabin Comfort - Airflows Analysis [5].

HVAC Noise evaluations are generally done by conventional testing techniques. However, testing using the actual parts results in higher development cost. Also, HVAC prototype parts used for testing, takes longer time to develop and sometimes results in late detection of undesirable noises in the product. Hence, 3-D CFD and acoustic simulations are becoming an industry norm across the Automotive OEM's. Early detection in design flaws gives ample opportunities to fix them, enabling the design less susceptible to failure. There are some limitations to virtual product validation which are as under:

- $\quad$ Lack of a standalone FEM approach to capture frequencies between $20-20 \mathrm{kHz}$ [6].

- Validation with actual test results performed by OEM's

- Dearth of talent who are adept in CAE tools

- Slightly Expensive infrastructure and longer computational times.

However, the pros outweigh the cons and hence making virtual validation a necessary aid in product development.

1D simulation methods can be an alternate and innovative way to calculate the noise characteristics of the HVAC system. These methods allow faster validation of the duct design and HVAC components reducing the number of design iterations and saving time. In this paper, we are focusing on the $1 \mathrm{D}$ modelling of HVAC ducts using GT-Suite, in contrast to traditional acoustic testing and validation methods. The main goal of the present paper is to apply this method for predicting and optimizing the flow-induced noise contributions of an automotive HVAC system. The validation of the numerical results is achieved by comparing the Sound Pressure Level (SPL) at the passenger's ear locations to acoustic measurements performed in production vehicles and published by the Engineers at Fiat Chrysler Automobiles, USA [7].

\section{Methodology}

An automotive HVAC System is composed of various components like compressor, thermal expansion-valve, Condenser, Evaporator, HVAC unit, blower motor, ducts and louvres. This paper investigates the flow noise generated due to air flow measured at the HVAC duct exits with varying mass flow rates. We are assuming that the noises from all the above-mentioned 
components are ignored and only from front vents are taken into account. This is to simulate the condition when the HVAC unit operates only for fresh air circulations and other air egress vents are closed.

The following method was applied for the 1D acoustics simulation. First step is to design the CAD geometry in SOLIDWORKS and import it into the GEM-3D environment. Next step is to discretize the 3D model into smaller volumes before it is converted into a GT-ISE 1D model. Finally, mass flow rate was applied at the inlet of the Air Box and microphones were attached at the outlets to simulate real test case scenarios. Basic flowchart of our noise measurement technique has been shown in Figure 2.

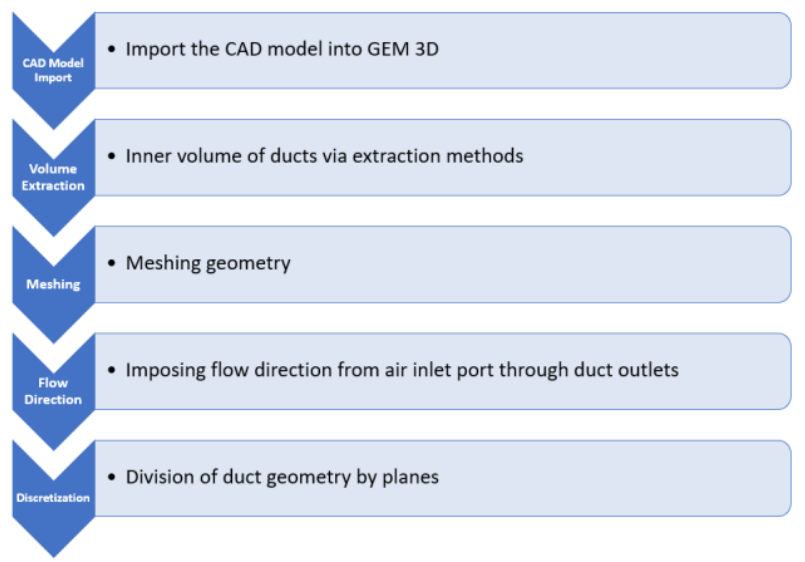

Figure 2. Process Flowchart

\subsection{CAD designing}

HVAC Unit is attached on the front frame under the front panel. The HVAC Unit itself is counted as a noise excitation source for vehicle interior. Owing to the operation of blower fan blades, structure-borne, air-borne and fluid-borne noises occur and are detected by human ears in the cabin interior. This study focuses only on the fluid-borne noise levels due to air flow. An automotive HVAC system operates in different modes namely defrost activation, foot room, ventilation mode and their combinations. Figure 3 represents a sample climate control board and the location of relevant duct outlets during ventilation mode.

Filtered air from the blower enters the cabin interior via ducts. Ducts are located underneath the front panel; designing it is an extremely challenging task due to the frequent design changes, safety regulations, cost-reduction or design space issues. Figure 4 shows the 3D geometry which was designed using the
Solidworks CAD package. Our workflow started with creating 3D geometry in Solidworks and was exported in step/stl format to the GEM3D package of GT-Suite.

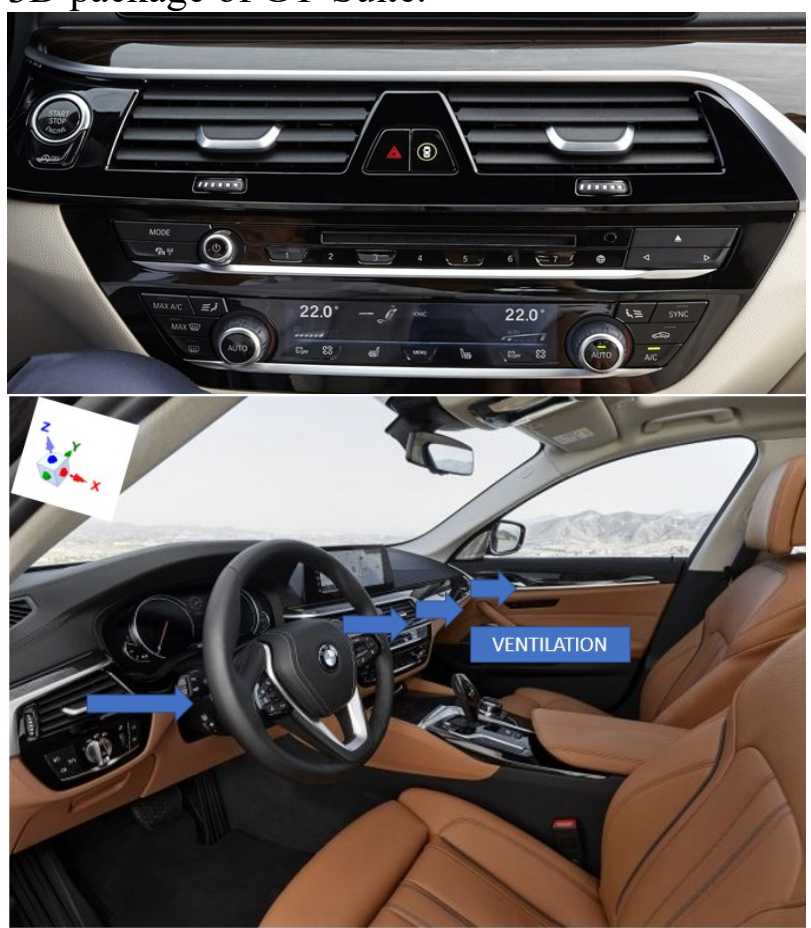

Figure 3. HVAC System climate control and configuration and on the front panel [8]

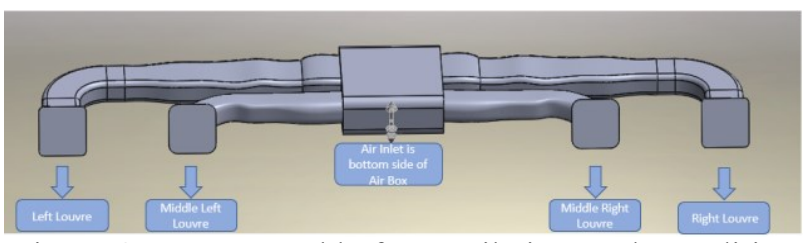

Figure 4. Duct Assembly for ventilation mode condition

\subsection{Model Discretization}

Discretization is the splitting of large parts into smaller sections to improve a model's accuracy. When a volume is discretized into smaller subvolumes, by selecting discretization length to be shorter than the pipe length, the result will be the same as if several shorter single-volumes would have been used instead of one longer duct. After the discretization is complete, the model is converted into a GTM map file where we have installed microphones on the exits i.e. in front of duct openings to analyze the flow noise which is governed by its shape of the duct, the mass flow rate and a few geometrical parameters. Combined with all the factors it influences the acoustic properties of the duct.

\subsection{Simulation}

The GT-map of the duct after discretization is complete and can now be accessed by the user 


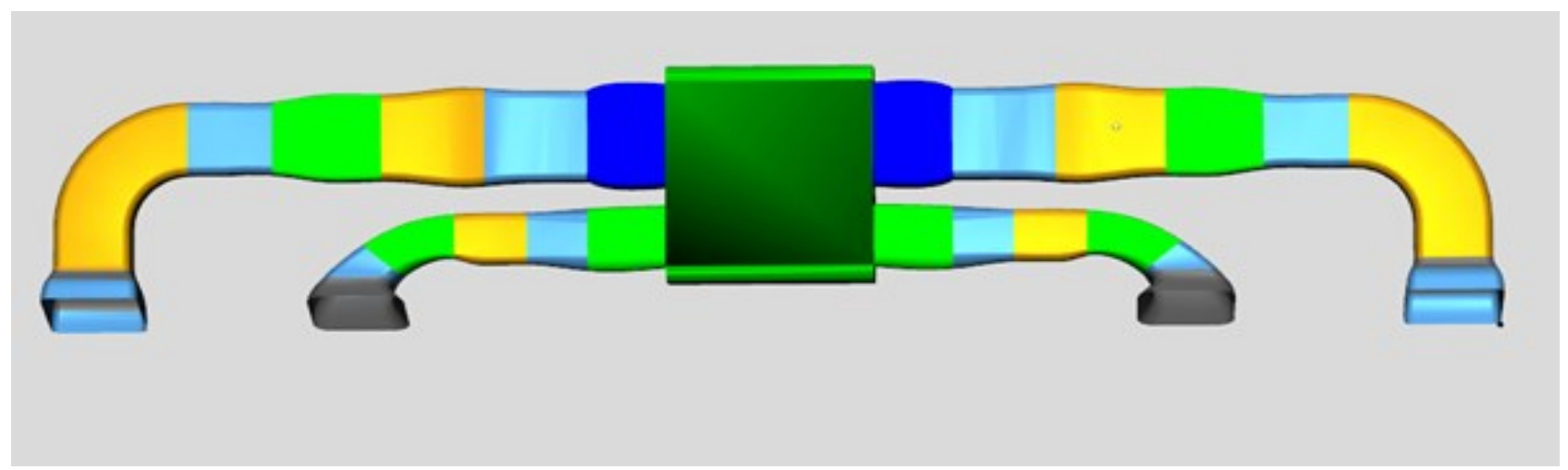

Figure 5. Discretized Duct Model

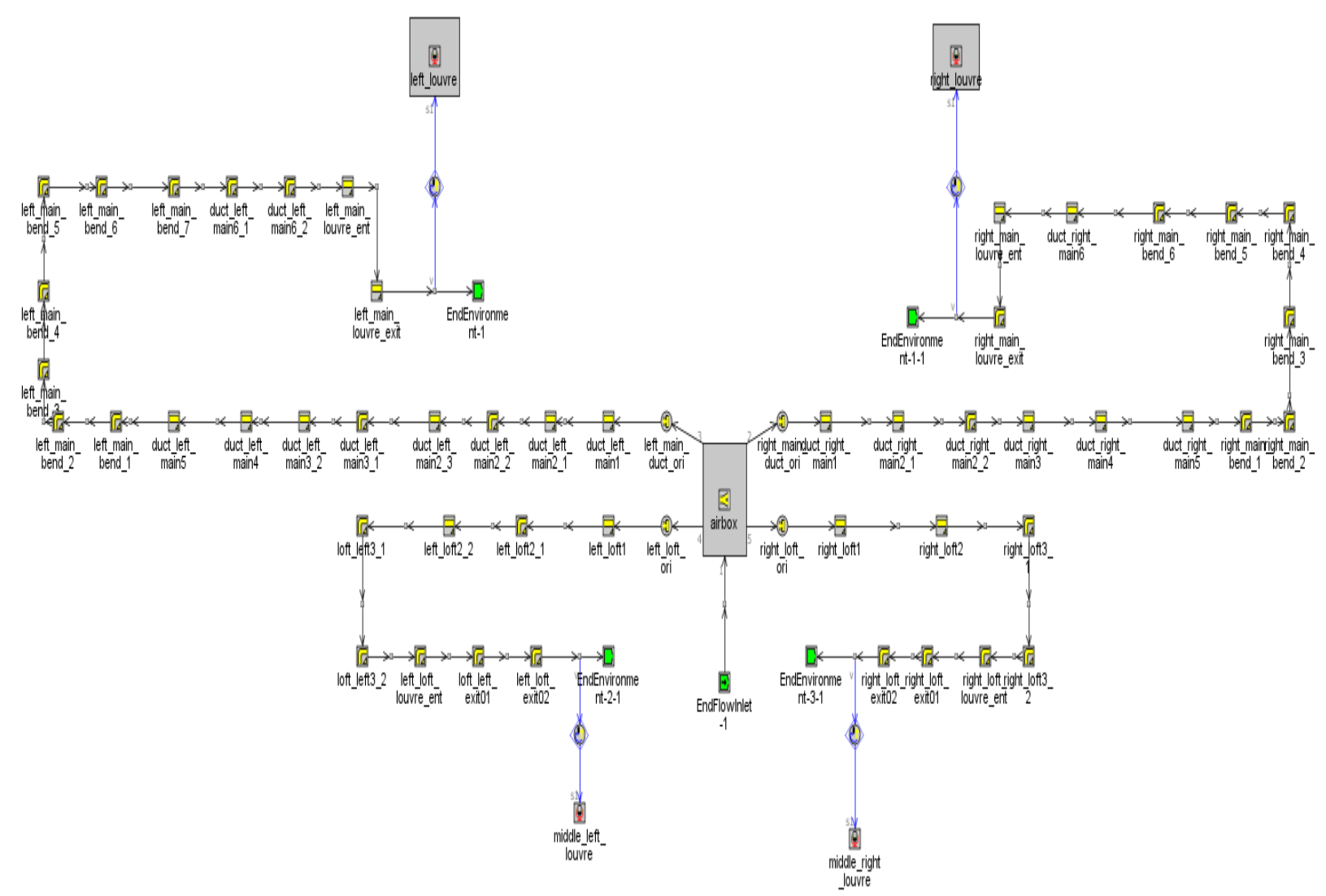

Figure 6. 1D model of HVAC Ducts

in GT-ISE. The map simply looks like a block of small volumes whose properties can be changed as per the user, where each block is represented by a single volume, and every pipe is divided into more volumes. These volumes are connected by symmetrical flow coefficient smooth pipes and in the exits are the end environments which simulate the cabin environment conditions. We also added microphones, pressure and mass flow sensors at the end of each duct outlet. Microphones as acoustic sensors are attached to the duct outlets in ventilation modus as $5 \mathrm{~cm}+X$ direction (through driver) and $10 \mathrm{~cm}+Z$ direction through roof. Acoustic data is calculated via these 4 virtual microphones. Figure 6 shows the architecture of the 1D simulation model.

We are running three different cases where the mass flow rate of the air entering the system is varying and it is the reason for the flow noise generation. Mass flow rate vs. blower speed data is given in Table 1. This data is used as a reference from a test bench data [7].

\section{Simulation Results}

In this paper we are running three different cases (minimum, middle and maximum air-flow) where the mass flow rate of air entering the system varies. Results are investigated by using Mass Flow Rate distribution, Sound Pressure Level (SPL) and Fast Fourier Transformation (FFT). 
Table 1. Excitation inputs; mass flow rate vs blower speed

\begin{tabular}{ccc}
\hline Case & $\begin{array}{c}\text { Mass Flow } \\
\text { Rate (g/s) }\end{array}$ & $\begin{array}{c}\text { Blower Speed } \\
\text { (rpm) }\end{array}$ \\
\hline 1 & 32.76 & 960 \\
2 & 111.44 & 3080 \\
3 & 147.50 & 3853 \\
\hline
\end{tabular}

Boundary conditions are also described in Table 2.

Table 2. Boundary conditions of the model

\begin{tabular}{cc}
\hline Parameter & Value \\
\hline Air Density & $1.18 \mathrm{~kg} / \mathrm{m} 3$ \\
Static Pressure at inlet & $700 \mathrm{~Pa}$ \\
section & \\
\hline
\end{tabular}

3.1. Mass flow rate investigation: These mass flow rates at the inlet section were chosen from the test bench data, main flow from the air box is distributed throughout four ducts. Hence, we tried to understand the influence of the symmetrical design into the flow distribution. Table 3 shows the mass flow rate values at the outlet of all ducts.

Table 3. Mass flow rate values at duct outlets

\begin{tabular}{lccc}
\hline \multirow{2}{*}{$\begin{array}{c}\text { Flow Sensor } \\
\text { Location }\end{array}$} & \multicolumn{3}{c}{$\begin{array}{c}\text { Average Mass Flow Rate } \\
(\mathbf{g} / \mathbf{s})\end{array}$} \\
\cline { 2 - 4 } & Case 1 & Case 2 & Case 3 \\
\hline Left Louvre & 13.97 & 47.81 & 63.22 \\
Centre Left Louvre & 4.07 & 13.91 & 18.49 \\
Centre Right Louvre & 4.21 & 14.43 & 19.19 \\
Right Louvre & 10.40 & 35.21 & 46.50 \\
Sum & 32.65 & 111.36 & 147.40 \\
\hline
\end{tabular}

It can be observed that there is a small difference in mass flow rates between the left and right duct system in spite of being symmetrical in design. Hence, it can be stated that although total mass flow rate is conserved, flow is not distributed symmetrically. We calculated the mass flow skewness factor of the geometry and found out that the left side of the ducts are getting an average of $19.4 \%$ higher mass flow than the right ducts.

$S=\frac{\left(M_{\text {dot }} \text { left }-M \text { dot }_{\text {rigt }}\right) \cdot 100}{M d o t_{\text {left }}}$

Table 4. Mass flow Skewness factor of the ducts

\begin{tabular}{cccc}
\hline Specifications & \multicolumn{3}{c}{ Descriptions } \\
\hline Left duct air mass (g/s) & 18.04 & 61.72 & 81.71 \\
Right duct air mass (g/s) & 14.61 & 49.64 & 65.69 \\
Skewness (\%) & 19.01 & 19.57 & 19.60 \\
\hline
\end{tabular}

3.1. Microphone Pressure Level: Figure 7 shows the sound pressure levels $(\mathrm{dB})$ of the microphones for all ducts.
As it is expected from Figure 7, SPLs are proportional to mass flow rate. Horizontal axis shows the case number where in each case different mass flow of air has been applied as inputs and Vertical Axis. Once the mass flow rate increases from Case 1 to Case 3, SPLs are also going up. Figure 7 also validates Table 3 . As the similar excitation levels at the outlets lead to the similar SPLs.

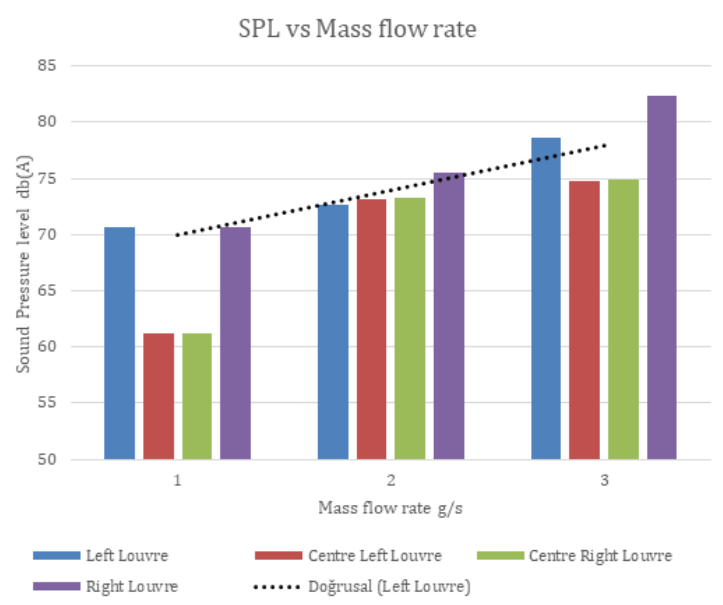

Figure 7. Microphone Sound Pressure Level vs mass flow rate at the ducts

3.3. Sound Pressure Levels (SPL): These values are represented by using FFT methods. FFT graphics are achieved by processing 10 second constant excitation signals. All cases are investigated using the same FFT parameters as total duration for runs and $0.5 \mathrm{~s}$ time interval.

SPL graphics are shown just for all ducts in order to understand the influence of mass flow rate. Figure 8 shows the A-Weighted SPL's for all louvres for different loadings.

Figure 8 shows that noise levels can be predicted with 1D simulation methods. Critical noise levels for $333 \mathrm{~Hz}$ and $666 \mathrm{~Hz}$ and can be seen. SPLs were calculated until $5 \mathrm{kHz}$; two main peaks have been calculated below $1000 \mathrm{~Hz}$. Although each critical case or acoustic resonances cannot be achieved, overall sound pressure level value as " $75 \mathrm{~dB}(\mathrm{~A})$ ") calculated conveniently and show the similar values according to real test results [7]. Scalar value differences between our results and test bench results are due to the difference in the distance of the microphone from the source. In our case, calculations are done in the near field. Thus, sound pressure levels are higher than compared test results. Although the geometry is symmetric, discretized model in Figure 5 could have some transition problems due to the 


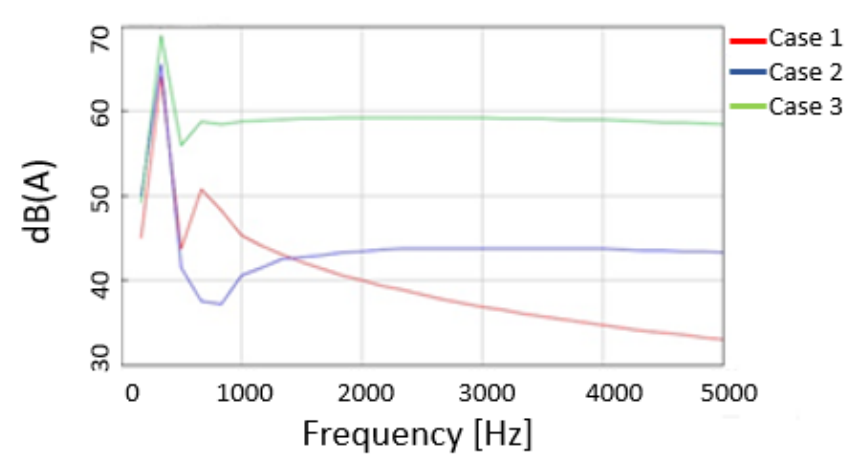

Left Louver

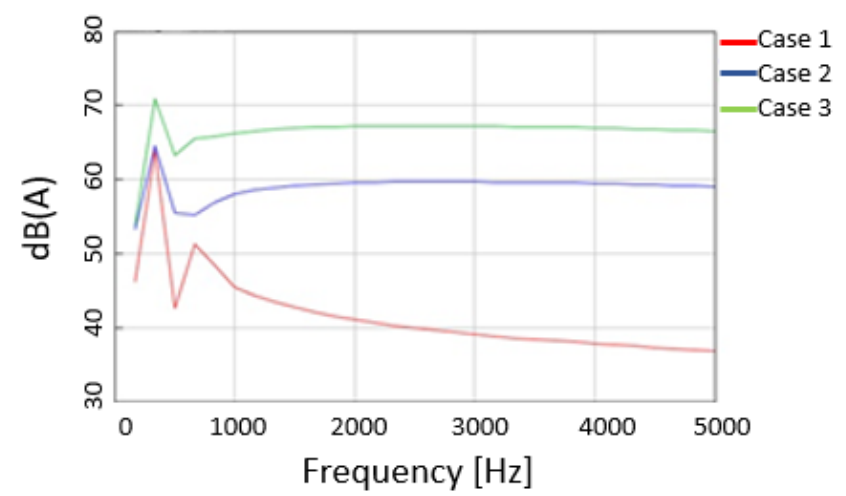

Right Louver

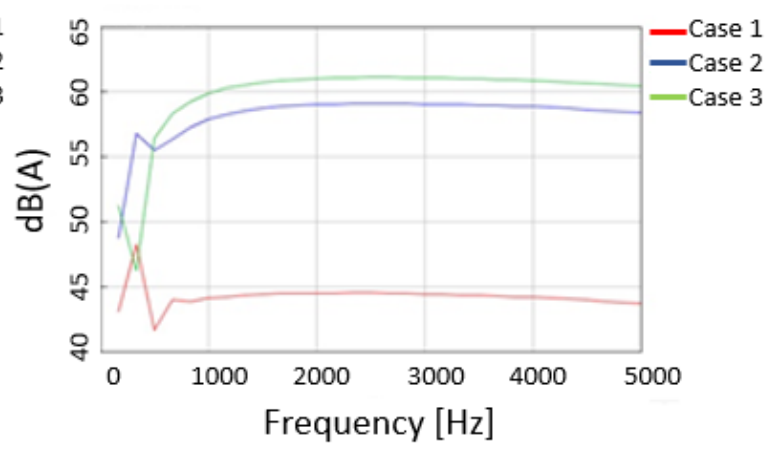

Left Centre Louver

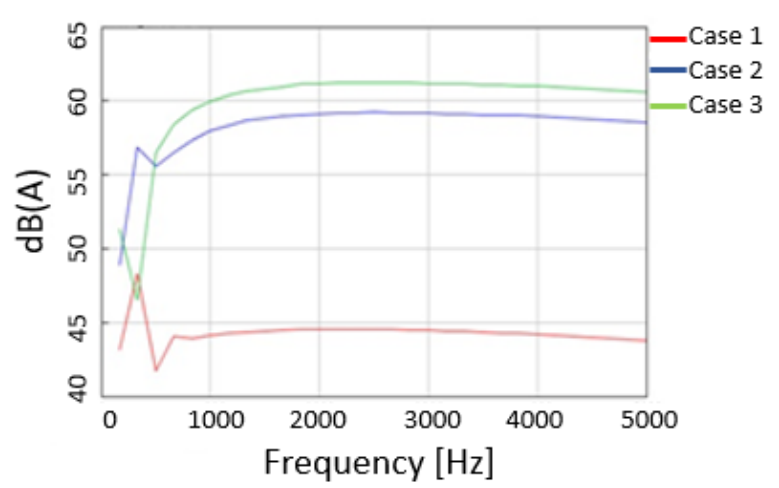

Right Centre Louver

Figure 8. A-weighted SPL's

transition of mathematical model from $3 \mathrm{D}$ to 1D. For instance, mathematical model ignores the parabolic shapes and calculate it rectangular via linear lines. Therefore, a peak is observed on the Left Louver at Case 1 higher amplitude than Case 2 in the Figure 8.

\section{Conclusions}

By looking at the results, we can conclude that results of our 1D acoustic simulation are in line with the physics of flow i.e. higher the mass flow rate higher the SPL. It also is a good tool to perform acoustic analysis in parallel to traditional aeroacoustics simulations methods and validation methods. We were able to develop a process for calculating the SPL's for any duct, starting from CAD designing, discretization and setting up sensors. This methodology is developed to reduce computational time required for setting up an actual test and engineering labor. Mass flow rate variations and microphone locations are in accordance with the real vehicle acoustic measurements. Although the geometry is symmetric, flow is not separated as symmetrically. It motivates to investigate new directions to analyze the comparison between
$1 \mathrm{D}$ and CFD results.

Microphone pressure values and SPL levels represent the comprehensive results compared to referenced measurement results. Although SPL diagrams are not precise enough to determine the sound characteristics for each specific frequency, a general trend has been validated which follows the physics.

\section{References}

1. Aissaoui A., Tupake S R., Bijwe V., Meskine M., Perot F., Belanger A., Vaidya R.J., "Flow-Induced Noise Optimization of SUV HVAC System using a Lattice Boltzmann", SAE Technical Paper, 2015-01-2323, DOI: 10.4271/2015-01-2323, July 06, 2015.

2. Eckstein L., "Automotive Engineering III", RWTH Aachen University, Chapter 5, p.101-115.

3. Madani V. and Ziada S., "Aeroacoustic Characteristics of Automotive HVAC Systems", SAE Technical Paper, ISSN 01487191, April 14-17, 2008.

4. Kale G., Kulkarni M. A., Arun, S., Bhagate R., "NVH challenges and solutions to mitigate cabin noise in electric vehicles", IEEE, DOI: $\quad$ 10.1109/ITEC-India.2015.7386867, 
January 21, 2016.

5. http://cfdtraining.epizy.com/?i=1, 14/12/2020.

6. Karel, V., Genechten, B.V., Vandepitte, D., Desmet, W., "On the analysis of vibroacoustic systems in the mid-frequency range using a hybrid deterministic-statistical approach", Science Direct, Volume 89, Issues 11-12, Pages 868-877, DOI: 10.1016/j.compstruc.2011.03.002, June 2011.

7. Vasanth, B., Sathish, K., Govindarajalu, M., and Khan, M., "A Novel Approach to Predict HVAC Noise Using 1D Simulation," SAE Technical Paper, 2016-01-0249, DOI: 10.4271/2016-01-0249, 2016.

8. https://www.press.bmwgroup.com/glob al/article/detail/T0264349EN/the-new-bmw-5series-sedan?language=en, 17/05/2020. 